\title{
Identifying Pediatric Trauma Data Gaps at a Large Urban Trauma Referral Center in Santiago, Chile
}

\author{
${ }^{1}$ Etienne St-Louis, ${ }^{2}$ Daniel Roizblatt, ${ }^{3}$ Dan L Deckelbaum, ${ }^{4}$ Robert Baird, ${ }^{5}$ César V Millán \\ ${ }^{6}$ Alicia Ebensperger, ${ }^{7}$ Tarek Razek
}

\begin{abstract}
Background: Trauma registries contribute to improving trauma care, but their impact is highly dependent on the quality of the data. A simplified point of care pediatric trauma registry (PTR) was developed at the Centre for Global Surgery from the McGill University Health Centre (MUHC) for implementation in Low-middle income countries (LMICs). Pilot deployment was launched at a large urban trauma center in May 2016 in Santiago, Chile. Prior to deployment, we sought to identify missing data in existing trauma records in order to optimize PTR practicality and user benefit.
\end{abstract}

Materials and methods: The project was approved by the local Institutional Review Board. Retrospective chart review was conducted on trauma patients below the age of 15 who were evaluated at the emergency room (ER) of Hospital Dr. Sotero del Rio (HSR) between January 1st and June 30th 2015. Data missingness was evaluated for each component of the PTR (demographics, mechanism, injury and outcomes). Potential independent predictors of data missingness were evaluated using multiple linear regression.

Results: A total of 351 patients were included. Demographic data missingness ranged from $0 \%$ (age) to $95 \%$ (mode of arrival). Mechanism data missingness ranged from $6 \%$ (cause of injury) to $42 \%$ (site of injury). Injury physiology data missingness ranged from $37 \%$ (oxygen saturation) to $99 \%$ (respiratory rate). Interestingly, mean injury anatomy data missingness was significantly inferior to physiology data $(0.6 \%$ vs. $78.6 \%$, $\mathrm{p}<0.05)$. Outcome data missingness reached $54 \%$ at 2 weeks.

Conclusion: In resource-limited settings, high quality data is essential to guide responsible resource allocation. We

\footnotetext{
${ }^{1}$ Resident, ${ }^{2-4,6,7}$ Surgeon, ${ }^{5}$ Chief

${ }^{1}$ Department of General Surgery, McGill University Health Centre, Montréal, Québec, Canada

${ }^{2}$ Department of Trauma Surgery, Hospital del Trabajador Santiago, Chile

${ }^{3,7}$ Department of Trauma Surgery, McGill University Health Centre, Montréal, Québec, Canada

${ }^{4}$ Department of Pediatric Surgery, McGill University Health Centre, Montréal, Québec, Canada

${ }^{5}$ Department of Emergency, Hospital Dr. Sotero del Rio Santiago, Chile

${ }^{6}$ Department of Pediatric Surgery, Hospital Dr. Sotero del Rio Santiago, Chile

Corresponding Author: Etienne St-Louis, Resident, Department of General Surgery, McGill University Health Centre, Montréal Québec, Canada, e-mail: Etienne.st-louis@mail.mcgill.ca
}

believe implementation of a simplified trauma registry has the potential to reduce data gaps for pediatric trauma patients by streamlining trauma data collection at point of care. This should include streamlined data collection with a short per-patient completion time, and should forego attempts to collect data at 2 weeks, which has proven unsuccessful.

Keywords: Data quality, Injury surveillance, Missing data, Pediatric injury, Pediatric trauma, Santiago, Trauma registry.

How to cite this article: St-Louis E, Roizblatt D, Deckelbaum DL, Baird R, Millán CV, Ebensperger A, Razek T. Identifying Pediatric Trauma Data Gaps at a Large Urban Trauma Referral Center in Santiago, Chile. Panam J Trauma Crit Care Emerg Surg 2017;6(3):169-176.

Source of support: This research was supported by a Canadian Institutes of Health Research Canada Graduate Studies Award for Master's Students.

Conflict of interest: None

\section{ABSTRACTO}

Antecedentes: Los registros de trauma contribuyen a mejorar la atención traumatológica, pero su impacto depende en gran medida de la calidad de los datos. En el Centro de Cirugía Global del Centro de Salud de la Universidad de McGill se desarrolló un registro simplificado de trauma pediátrico en el punto de atención (PTR) para su implementación en países de ingresos medios bajos (LMIC, por sus siglas en inglés). El despliegue piloto fue lanzado en un gran centro de traumatología urbana en mayo de 2016 en Santiago, Chile. Antes del despliegue, se buscó identificar los datos faltantes en los registros de trauma existentes a fin de optimizar la practicidad PTR y el beneficio del usuario.

Métodos: El proyecto fue aprobado por la Junta de Revisión Institucional local. Se realizó una revisión retrospectiva de los pronósticos de los pacientes con traumatismos menores de 15 años que fueron evaluados en la sala de urgencias del Hospital Dr. Sotero del Río entre el 1 de enero y el 30 de junio de 2015. Se evaluó la falta de datos para cada componente del PTR , Mecanismo, lesión y resultados). Los potenciales predictores independientes de la falta de datos se evaluaron mediante regresión lineal múltiple.

Resultados: Se incluyeron 351 pacientes. La falta de datos demográficos osciló entre $0 \%$ (edad) y $95 \%$ (modo de llegada). La falta de datos del mecanismo osciló entre el $6 \%$ (causa de la lesión) y el $42 \%$ (sitio de la lesión). La falta de datos de la fisiología de lesiones osciló entre el 37\% (saturación de oxígeno) y el 99\% (frecuencia respiratoria). Curiosamente, los datos de anatomía de lesión media faltantes fueron significativamente inferiores a los datos fisiológicos $(0,6 \%$ vs $78,6 \%, p<0,05)$. La falta de datos de resultados alcanzó el $54 \%$ a las 2 semanas. 
Conclusiones: En entornos de recursos limitados, los datos de alta calidad son esenciales para orientar la asignación responsable de recursos. Creemos que la implementación de un registro de trauma simplificado tiene el potencial de reducir las lagunas de datos para los pacientes pediátricos traumatizados mediante la racionalización de la recogida de datos de trauma en el punto de atención. Esto debería incluir una recolección de datos simplificada con un tiempo de finalización corto por paciente, y debería renunciar a los intentos de recopilar datos a las 2 semanas, lo que ha resultado infructuoso.

Palavras-chave: Calidad de los datos, Datos faltantes, Lesiones pediátricas, Registro de traumatismos, Santiago, Traumatismos pediátricos, Vigilancia de lesiones.

\section{BACKGROUND}

Trauma remains a leading cause of mortality in children worldwide. ${ }^{1}$ The development of trauma registries has contributed to improving trauma outcomes in a variety of settings, including resource-poor environments. ${ }^{2}$ However, the impact of trauma registries is highly dependent on the quality of the data within. ${ }^{3}$ Although data quality can be evaluated according to a multifactorial paradigm, missing data is a basic parameter that can be used to easily assess the quality of data collection and effectiveness of a given data collection tool. ${ }^{3-6}$

We aim to establish a clinical and research partnership between HSR and MUHC for pediatric injury surveillance. This initiative entails the development and deployment of a PTR that can be used for the purposes of epidemiologic analysis, research, quality improvement, outcomes benchmarking and decision-making for resource allocation. In this pilot study, we set out to evaluate the readiness of HSR for PTR deployment. To do so, our objectives were to describe the epidemiology of pediatric trauma at HSR, to identify gaps in data collection using existing HSR health record systems, and to use the information from this pilot study to inform our future efforts to optimize the utility of a prospective PTR within our partnership. We hypothesize that missing data is significant in existing health records at HSR which may result in bias and negatively impact health care resource allocation decisions based on incomplete data.

\section{MATERIALS AND METHODS}

\section{Study Setting}

Hospital Dr. Sotero del Rio is a large urban referral center for pediatric trauma. It is located in South-Eastern Santiago, Chile, and serves a population of approximately 2 million people. The HSR is not a stand-alone pediatric hospital. Two main pavilions are located on the hospital campus, one of which is dedicated to the care of children. The pediatric pavilion has a separate emergency department, for patients 15 years-old and younger. The Chilean trauma system is regionalized such that HSR serves several districts of South-Eastern Santiago. This institution's emergency department uses free-text style open charts, rather than predetermined admission, history, and physical examination templates. Full pediatric general surgery and orthopedics coverage is available, while pediatric neurosurgery consultants provide coverage 6 days per week, on average. In addition, HSR is not a dedicated burn center. Electronic health records are used at HSR. A patient-specific medical record number can be used to browse multiple data interfaces which captures information on the different phases of patient care, such as, emergency department visits, hospitalizations, and ambulatory clinic visits.

\section{Data Collection}

After obtaining approval from the HSR institutional research Ethics Review Board, we obtained access to the electronic health records of all trauma patients who were seen at the HSR pediatric emergency department in the 6-month period between January 1st, 2015 to June 30th, 2015. Retrospective chart review was performed for patients who met inclusion criteria: Patients aged between 0 and 15 years who were seen by pediatric general surgery, orthopedics or neurosurgery for traumatic injury and who required hospitalization or transfer to another institution for definitive care (including return to hospital of origin with planned follow-up visit at HSR). Patients were excluded if they met the following exclusion criteria: Age greater than 15 or discharge home from ER. Variables were collected from existing health records according to a pilot PTR adapted from the McGill Centre for Global Surgery iTrauma Trauma Registry. The "iTrauma", which is a trauma registry designed to capture essential data on adult trauma patients in differently-resourced environments. Though it was originally developed as a paper-based registry (Appendix 1), it has since been made available as an application available on iOS, the mobile operating system for Apple devices, and functions with or without an internet connection. ${ }^{7}$ The pilot PTR was adapted from iTrauma to capture relevant data for pediatric trauma patients and finally translated into Spanish and approved by pilot institution (Appendix 2). The variables collected fall into four major categories: (1) Demographics and logistics, (2) mechanism, (3) injury, and (4) outcomes. Missing data were recorded as not-available. After pilot data was collected, this was presented at the weekly pediatric surgery service rounds and qualitative feedback was sought for discussion.

\section{Analysis}

Summary statistics are reported as appropriate for all variables, including missing data. For a given variable, 


\section{Data Collection Form}

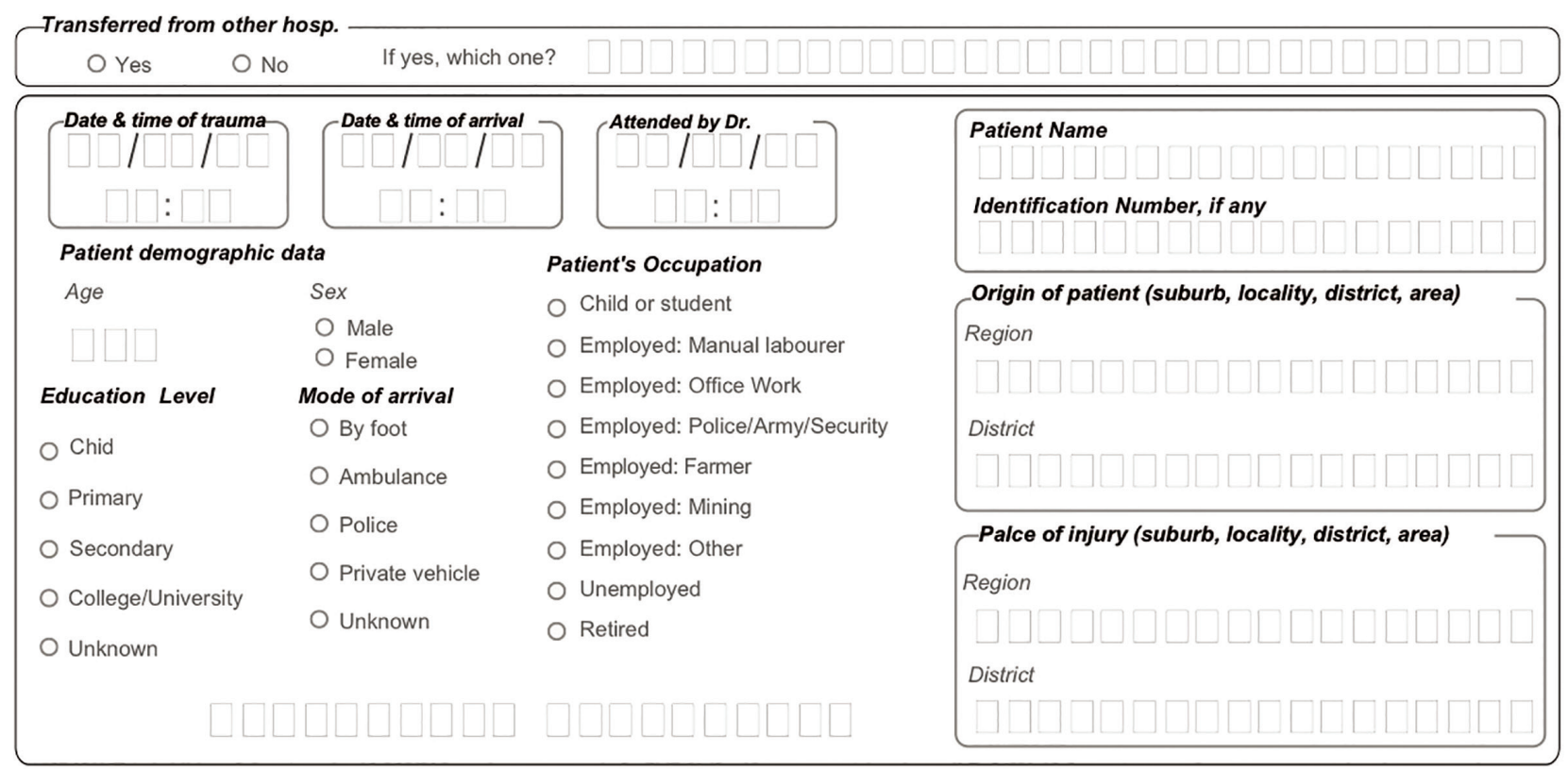

Mechanism
Cause of Injury
O Motor Vehicle Collision
O Fall
O Blunt Assault
O Stab/Cut
O Gunshot
O Blast/Landmine
O Burn
O Drowning
O Bite

Settings $\square \square \square \square \square \square \square \square$
O Transportation Accident
O Work
O Home
O School
O Leisure/Sport
O Unknown
Intent
O Unintentional/Accidental
O Self-inflicted
O Assault
O Unknown
Alcohol
O No
O Suspected/Confirmed $\square$
O Unknown
$\square \square \square$
$\square$

Road Traffic Incident

Motor Vehicle Collision

Car

O Motorbike

O Tricycle/Triporter

Bicycle

O Unknown

Role on the road

O Driver

Passanger

O Pedestrian

O Unknown

Type of Vehicle

O Private Vehicle

Public Transit

O Commercial Vehicle

Helmet

Y Yes

O No

O Unknown

Seatbelt Use

$\bigcirc$ Yes

No

Unknown

Physician Signature

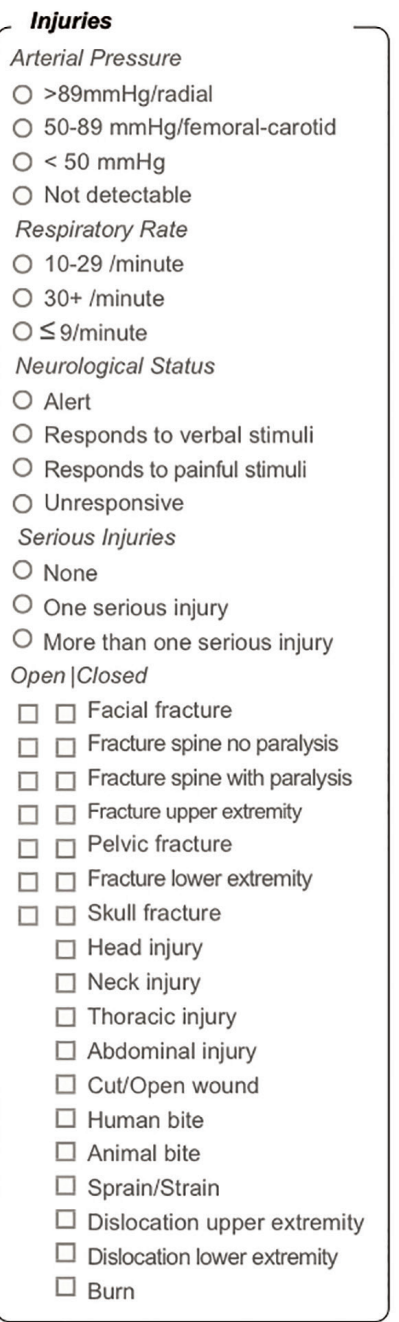

Outcome

Outcome from casualty department

Treated and sent home

O Admitted to hospital ward

Taken to operating theatre

O Admitted to intensive care

O Died

O Referred to another hospital

Unknown

If referred, which hospital?

Outcome filed by (MD, nurse, clerk)

Outcome at 2 weeks

O Discharged

O Ran away

O Admitted to hospital

O Died

OReferred to another hospital

OUnknown

If referred, which hospital?

Outcome filed by (MD, nurse, clerk)

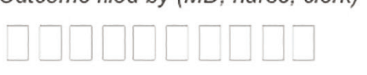

Appendix 1: iTrauma minimal data set 
GLOBAL SURGERY

Trauma Registry

Data Collection Form

iTrauma

McGill University Health Centre

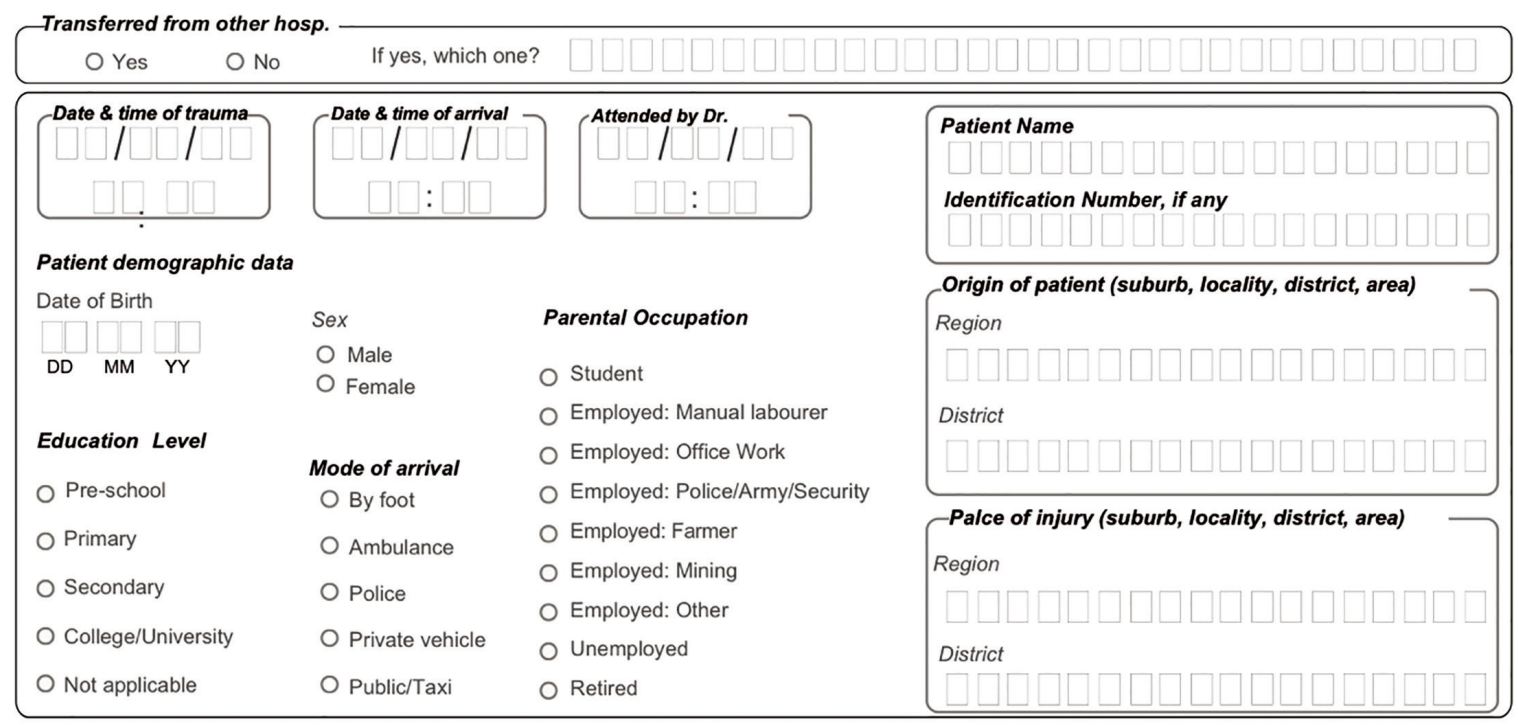

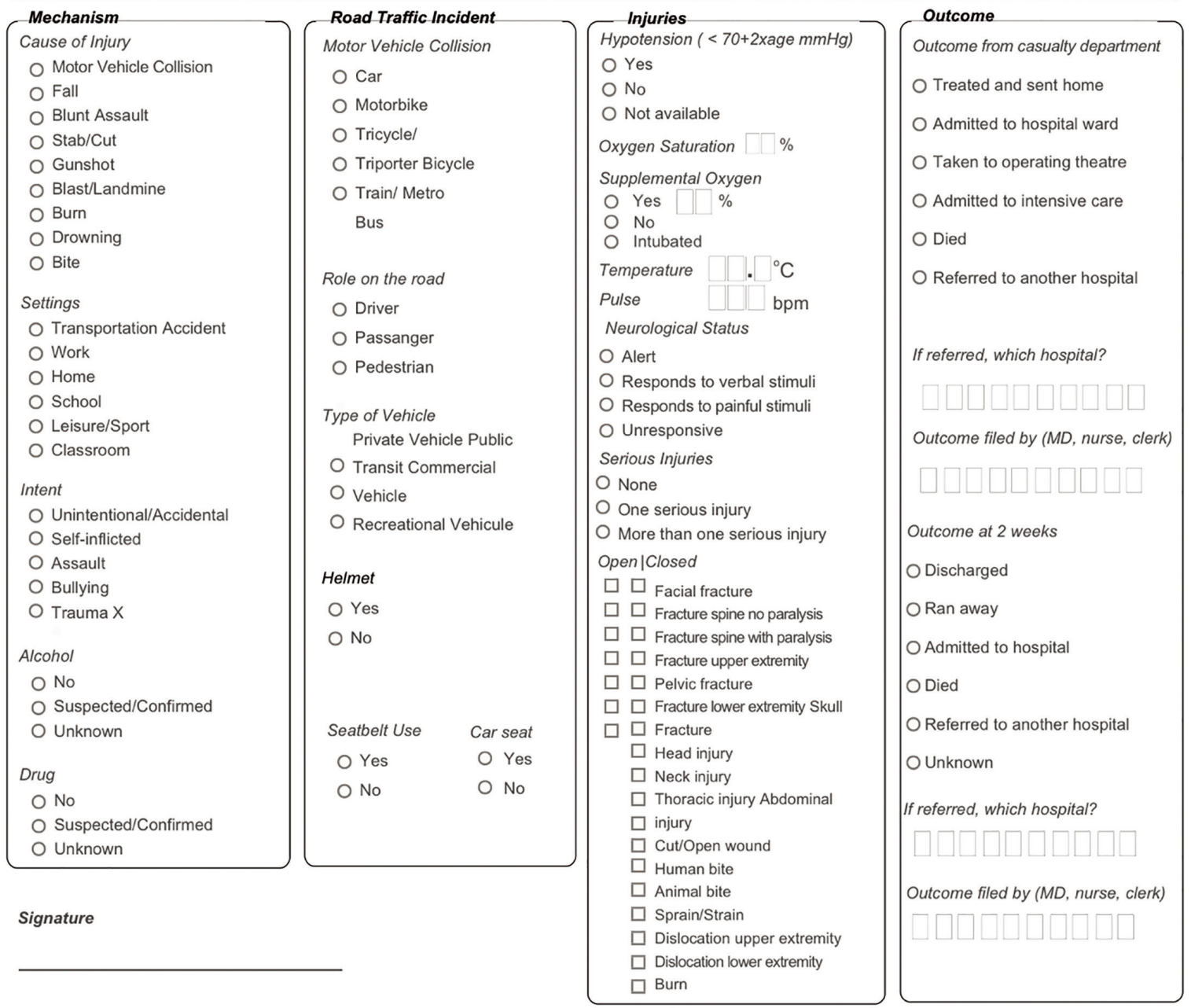

Appendix 2: Pilot PTR (adapted for children from McGill University Centre for Global Health iTrauma Minimal Data Set) 


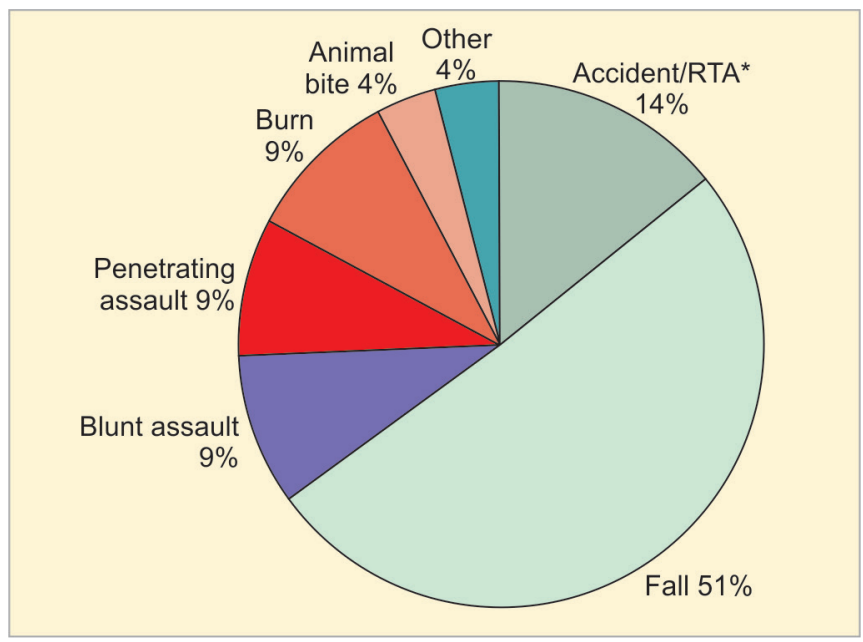

Graph 1: Distribution of injury mechanisms $(n=336)$ RTA: Road traffic accident

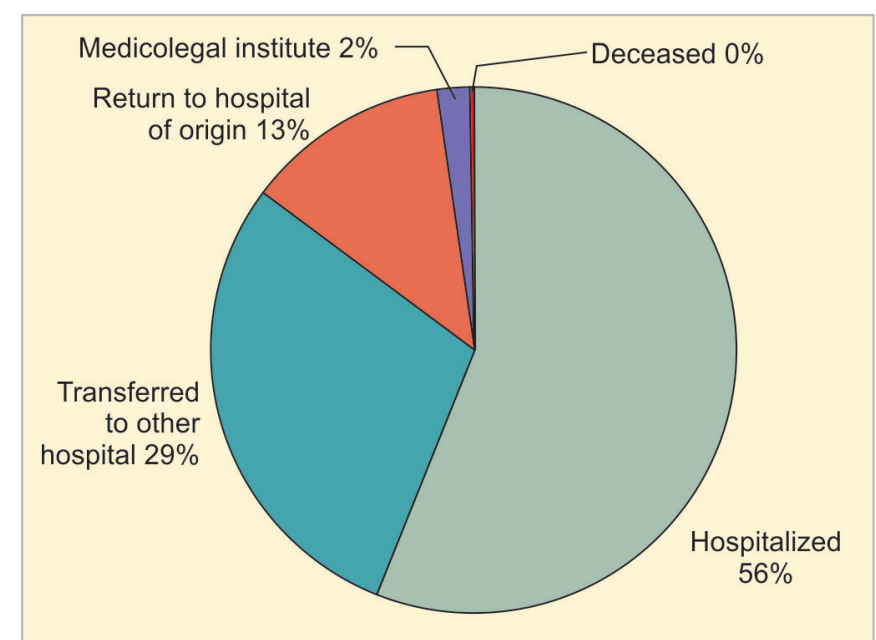

Graph 2: Distribution of patient disposition from emergency department $(n=351)$

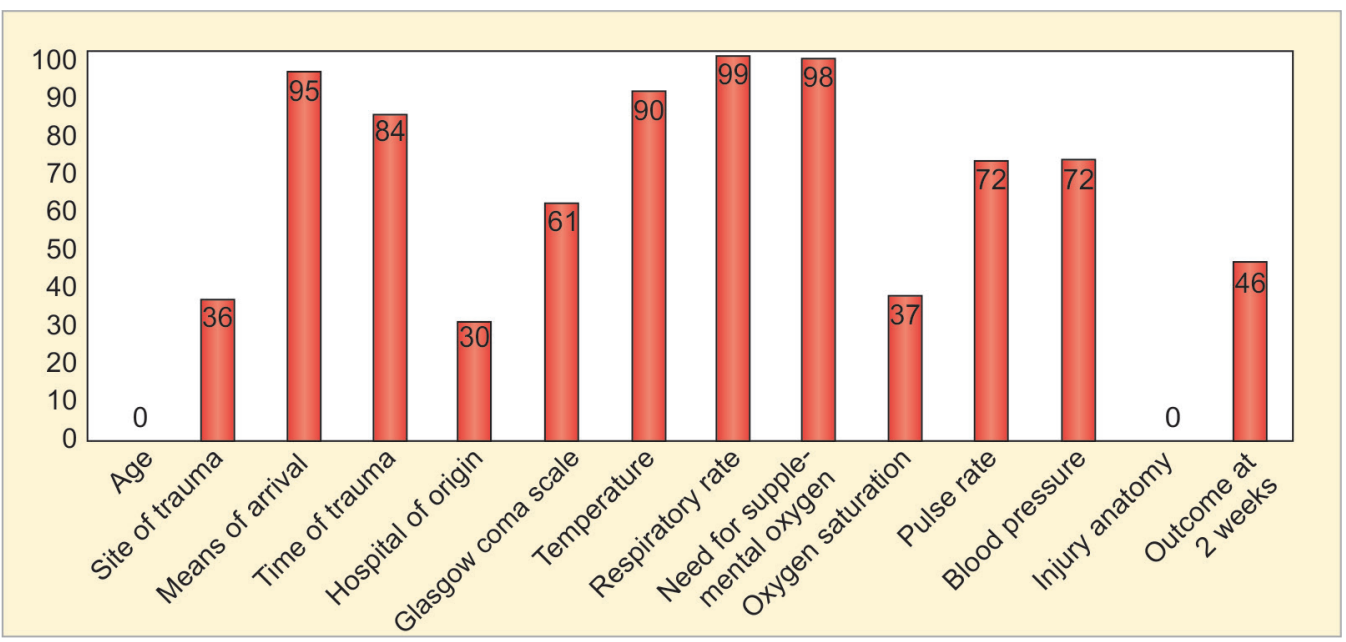

Graph 3: Percentage of missing data per variable

data missingness is expressed as a fraction of missing data points over total observations. For a given patient, data missingness is expressed as a fraction of missing data points over total number of variables. Potential predictors of individual patient data missingness were explored using univariate linear regression. These included season, weekend, gender, consultant and age. Variables that correlated with individual patient data missingness on univariate analysis $(p<0.25)$ were evaluated using multiple linear regression.

\section{RESULTS}

\section{Descriptive Statistics}

We included 351 patients, of which 234 (66\%) were female. Median age was 5 (2-9). Approximately $48 \%$ of the patients were seen by pediatric general surgery, $28 \%$ were seen by neurosurgery and $24 \%$ were seen by orthopedics. A majority of the injuries (60.1\%) occurred within the Puente Alto district, where HSR is located. The remaining
$39.9 \%$ of patients were injured in surrounding five districts, including Pirque, San José de Maipo, La Granja, La Florida, La Pintana, and San Ramon. Approximately half the patients who presented, sustained a fall. The mechanisms and disposition of patients are presented in Graphs 1 and 2 respectively. Of all patients who were hospitalized, 83\% underwent an operative intervention, and $26 \%$ were admitted to the intensive care unit at some point during their stay.

\section{Per-variable Data Missingness}

The range of per-variable missing data was 0.6 to $100 \%$. Demographic data regarding means of hospital arrival and time of trauma were missing in upwards of $80 \%$ of cases. Physiologic variables were also missing in large proportions. Percentages of missing data are presented in Graph 3. Basic hemodynamic variables that one might expect to find recorded in any patient's chart, not to mention a trauma patient's chart, such as, blood pressure and pulse rate were missing in $72 \%$ of patients. 
Table 1: Coefficients from simple linear regression, representing expected change in percentage of per-patient missing data, along with $\mathrm{p}$-values

\begin{tabular}{lcc}
\hline Variable & Coefficient & $p$-value \\
\hline Gender (female vs. male) & -0.013 & 0.080 \\
Age & 0.0004 & 0.327 \\
Season (winter vs. summer) & 0.074 & $<0.01$ \\
Consultant specialty (neurosurgery & -0.056 & $<0.01$ \\
vs. general pediatric surgery) & & \\
Weekend vs. weekday & -0.008 & 0.330 \\
\hline
\end{tabular}

Temperature, respiratory rate and need for supplemental oxygen were missing in upwards of $90 \%$ of patients. The least frequently missing physiologic variables were glasgow coma scale and oxygen saturation, at 61 and $37 \%$ respectively. However, anatomic injury data only had a $0.6 \%$ overall rate of missingness. Not surprisingly, follow-up data at 2 weeks was also problematic. It was identifiable in only $54 \%$ of patients despite integrated electronic health records.

\section{Predictors of Per-patient Data Missingness}

Univariate linear regression analysis was performed using the following potential predictors of missing data: Gender, age, season, consultant specialty or weekend. Results of the univariate linear regression analysis are shown in Table 1. Because they were identified as potential independent predictors of per-patient missingness, the following variables were included in the multiple linear regression: Gender, season, and consultant specialty (Table 2). Among these, season and consultant specialty were found to be independent predictors of proportion of per-patient missing data. Specifically, a patient presenting in winter compared to summer, with all else being equal, is expected to have a $7.7 \%$ increase in proportion of missing data $(\mathrm{p}<0.01)$. Similarly, a patient seen by neurosurgery upon presentation, with all else being equal, is expected to have a $6.4 \%$ decrease in proportion of missing data $(\mathrm{p}<0.01)$.

\section{DISCUSSION}

We identified several possible explanations for the large amounts of missing data. We can speculate that the multiple interfaces of the electronic health record system, capturing patient data at various phases of care may be partly responsible, as their integration is not yet seamless. For example, emergency department records on one interface may be left incomplete by the consulting physician who plans to include a summarized version of the findings in her admission note on another interface. Furthermore, feedback at service rounds from local collaborators included anecdotal explanations that fundamental
Table 2: Coefficients from multiple linear regression model including variables achieving $p<0.1$ on simple linear regression, representing expected change in percentage of per-patient missing data after adjustment for all other variables, along with $p$-values

\begin{tabular}{lcc}
\hline Variable & Coefficient & $p$-value \\
\hline Gender (female vs. male) & -0.008 & 0.1512 \\
Season (winter vs. summer) & 0.077 & $<0.01$ \\
Consultant specialty & -0.064 & $<0.01$ \\
(neurosurgery vs. general & & \\
pediatric surgery) & & \\
\hline
\end{tabular}

physiologic data are not necessarily recorded in the patient chart, even though they are consistently measured. Often, this is due to inadequate time in an overcrowded emergency department, particularly in the winter months when the number of visits for respiratory illness increases drastically. A quarterly administrative report produced by HSR indicates that although the number of emergency visits almost doubles in the winter months, the average wait time for patients to see a physician is only minimally increased, which reflects the expedited triage practices that this particular emergency department has adopted. The quantitative analysis we performed corroborates this subjective experience of the providers. In addition to season, we found that the specialty of the consultant who evaluated the child had a significant effect on the percentage of missing data recorded in the chart. One can only speculate as to the cause of the increased meticulousness of neurosurgeons in data recording, although liability concerns or lower relative volume of nontraumatic emergency consults may have contributed. Other potential predictors of data missingness, such as patient gender, day of the week (school day vs. weekend), and patient age were not significant on linear regression.

As trauma registries proliferate in $\mathrm{LMICs},{ }^{8,9}$ there have been a growing number of studies examining the quality of data within these registries. ${ }^{3,10-12}$ As stated by Porgo, et al, problems of data quality affect the reliability of said data in inform clinical decision-making, resourceallocation planning, and any quality improvement initiative. ${ }^{3}$ There has been widespread recognition that some existing and well-established trauma registries, such as, the International Trauma Registry in Latin America and the Caribbean regions, could benefit from integrating more rigorous data quality measures. ${ }^{10,11}$ It is important to note, however, that definitions of data quality vary significantly within the published literature, and methods described for evaluating such quality in trauma registries are inconsistent. ${ }^{12}$

In the growing field of global surgery, there is no doubt that trauma is a central driver of morbidity and mortality among the young and productive members of society, across all income levels. ${ }^{13}$ In 2015, the seminal work by 
the Lancet Commission on Global Surgery (LCoGS) ${ }^{14}$ reaffirmed the primordial importance of essential surgical services as a health care priority. This position statement, reinforced by the Disease Control Priorities 3rd edition volume on Essential Surgery ${ }^{15}$ and the World Health Assembly resolution A68.15, ${ }^{16}$ resulted in many studies describing the classification and measurement of unmet surgical disease. ${ }^{17-19}$ However, many of these studies and foundational documents, including the LCoGS estimates of surgical burden, DALYs and economic impacts are estimates based on models derived from sparse and incomplete data. As Margaret Chan of the World Health Organization aptly warned, "the real need is to close data gaps, especially in low- and middle-income countries, so that we no longer have to rely so heavily on statistical modeling for data on disease burden" ${ }^{20}$ Indeed, the more high quality data can be gathered on trauma processes, care and outcomes in LMICs, the more empowered local health-care providers and stakeholders will be to make impactful improvements.

The present study has its limitations. In particular it is a retrospective chart review and therefore, conclusions about the readiness of HSR to collect data prospectively within the context of a new injury surveillance program cannot be definitively asserted. If the local providers and stakeholders view the implementation of a new PTR as intrinsically valuable, then the hope is that the necessary resources will be allocated to allow its successful maintenance through continued high quality data collection. Furthermore, there may be specific challenges at the pilot site which contributed to the issues of data completeness and therefore results may not be generalizable to other institutions. It is possible that the proportion of missing data would be less significant in other hospitals where admission templates are used, resulting in more uniform and complete data collection. These admission, history, and physical examination templates are widespread in many Latin-American hospitals, and may already contribute to improvements in data collection in those institutions.

\section{CONCLUSION}

The study has shown that multiple local factors can decrease the providers' ability to record even the most basic of data variables that would be expected in patient health records, regardless of whether or not it was part of a quality improvement or research project. Most prevalent of all such factors appears to be time, which is why we believe that a new PTR must have the appropriate number of variables, without being overly simplistic or too complex, and allow short per-patient completion time. Furthermore, we argue that such a new PTR should include data points that can be easily completed at point-of-care, given that existing health records show inadequate detail for retrospective TR completion.

\section{REFERENCES}

1. Mock C, Abantanga F, Goosen J, Joshipura M, Juillard C. Strengthening care of injured children globally. Bull World Health Organ 2009 May;87(5):382-389.

2. Moore $\mathrm{L}, \mathrm{Clark} \mathrm{DE}$. The value of trauma registries. Injury 2008;39(6):686-695.

3. Porgo TV, Moore L, Tardif PA. Evidence of data quality in trauma registries: a systematic review. J Trauma Acute Care Surg 2016 Apr;80(4):648-658.

4. Wang RY, Storey VC, Firth CP. A framework for analysis of data quality research. IEEE Transactions on Knowledge and Data Engineering 1995 Aug;7(4):623-640.

5. Hlaing T, Hollister L, Aaland M. Trauma registry data validation: essential for quality trauma care. J Trauma 2006 Dec;61(6):1400-1407.

6. O'Donoghue J, O'Kane T, Gallagher J, Courtney G, Aftab A, Casey A, Torres J, Angove P. Modified early warning scorecard: the role of data/information quality within the decision making process. The Electronic Journal of Information Systems Evaluation 2011;13(3):100-109.

7. Bouchard B, Bado J, Deckelbaum DL, Razek T. The implementation of an app-based dataset for injury data acquisition in Montevideo, Uruguay. Ann Glob Health 2016 MayJun;82(3):319-320.

8. O'Reilly GM, Cameron PA, Joshipura M. Global trauma registry mapping: a scoping review. Injury 2012 Jul;43(7):1148-1153.

9. O'Reilly GM, Joshipura M, Cameron PA, Gruen R. Trauma registries in developing countries: a review of the published experience. Injury 2013 Jun;44(6):713-721.

10. Bonilla-Escobar FJ, Birda V, Puyana JC. Evaluating data quality in trauma registries. J Trauma Acute Care Surg 2016 Nov;81(5):992-993.

11. Porgo VT, Moore L. Re: Evaluating data quality in trauma registries. J Trauma Acute Care Surg 2016 Nov;81(5):993.

12. O'Reilly GM, Gabbe B, Moore L, Cameron PA. Classifying, measuring and improving the quality of data in trauma registries: A review of the literature. Injury 2016 Mar;47(3): 559-567.

13. Mock C, Lormand JD, Goosen J, Joshipura M, Peden M. Guidelines for Essential Trauma Care. Geneva, World Health Organization, 2004. Available from: http://apps.who.int/ iris/bitstream/10665/42565/1/9241546409_eng.pdf; 2017 [accessed 17.06.17]

14. Meara JG, Leather AJ, Hagander L, Alkire BC, Alonso N, Ameh EA, Bickler SW, Conteh L, Dare AJ, Davies J, et al. Global Surgery 2030: evidence and solutions for achieving health, welfare, and economic development. Surgery 2015 Jul;158(1):3-6.

15. Mock CN, Donkor P, Gawande A, Jamison DT, Kruk ME, Debas HT. Essential surgery: key messages of this volume. In: Debas HT, Donkor P, Gawande A, Jamison DT, Kruk ME, Mock CN, editors. Essential surgery: disease control priorities, 3rd ed, Vol. 1. Washington DC: The World Bank 2015. Available from: https://openknowledge.worldbank.org/ handle/10986/21568 [accessed 17.06.17]. 
16. World Health Organization. Sixty-Eighth World Health Assembly (WHA68.15). Strengthening emergency and essential surgical care and anaesthesia as a component of universal health coverage. Available from: http://apps.who.int/gb/ebwha/ pdf_files/WHA68/A68_R15-en.pdf?ua=1 [accessed 04.04.17].

17. Poenaru D. The burden of pediatric surgical disease in lowresource settings: discovering it, measuring it, and addressing it. J Pediatr Surg 2016 Feb;51(2):216-220.
18. Poenaru D, Pemberton J, Cameron BH. The burden of waiting: DALYs accrued from delayed access to pediatric surgery in Kenya and Canada. J Pediatr Surg 2015 May;50(5):765-770.

19. Poenaru D, Ozgediz D, Gosselin RA. Burden, need, or backlog: a call for improved metrics for the global burden of surgical disease. Int J Surg 2014;12(5):483-486.

20. Chan M. From new estimates to better data. Lancet 2012 Dec 15;380(98590:2054. 